\title{
Biological Systems: Open Access
}

\section{Organ genomics: what can we learn?}

\section{Mun-Kit Choy}

Department of Medicine, University of Cambridge, UK

Genomics is broadly defined as a discipline concerning the study of the genomes of organisms, however, technically, it can have many different forms depending on the molecular levels or aspects: variomics focuses on sequence or structural variations, epigenomics on DNA or histone modifications, cistromics on cis-elements for transcriptional regulation, transcriptomics on transcribed genomic regions, and interactomics on three-dimensional chromosomal interactions. In medical research, cancer has become the "model disease" to receive all the attention from the genomicists especially with the recent development of high throughput sequencing technologies. In 2007, The International Cancer Genome Consortium was launched to coordinate a few synergetic efforts studying over 25,000 cancer genomes at the genomic, epigenomic and transcriptomic levels [1]. A public research consortium named the Encyclopaedia of DNA Elements (ENCODE) has also been launched to identify all functional elements in the human genome using various cell types including a number of cancer cell lines[2]. Recently, methods of studying chromosomal interactions have been coupled with high throughput sequencing, such as ChIA-PET [3] and Hi-C [4], to analyse the interactomes of cancer cells.

Despite the fact that cancer is the leading cause of death worldwide and, thus, being in the limelight of the scientific arena, it is an exceptional case of "gain-of-function" disease unlike other major organ-related diseases that are mostly "loss-of-function". The genomes within cells accumulate mutations throughout life due to exposure to mutagens or errors in replications. Some of these mutations can up-regulate growth genes or down-regulate growth suppressor genes so the cells "gain" advantages to grow and migrate and therefore become cancerous [2]. Nevertheless, some of these mutations may cause apoptosis or occur in functional genes leading to loss-of-function. One example is from the mice with a deficiency in CuZn superoxide dismutase (CuZnSOD). Without the CuZnSOD to dismutate superoxide radicals generated in the cytoplasm and nucleus, widespread oxidative damage and mutation accumulation were observed in the liver of the mice that presumably has a high oxygen metabolism and vulnerability to oxidative damage [5-7]. As a result, the liver cells in these mice show more occurrences of hepatocarcinogenesis and apoptosis, and reduced life span $[5,6]$.

Cancer genomics concentrates on the genomes of tumours, which are effectively a "clonal population" of a single mutant cell, trying to understand the transformation process. For organ genomics however, a metagenomic approach has to be used because of the lack of clonal expansion of the cell carrying the culprit mutation. A tissue sample from a failing organ represents a mixture of cells bearing various types of mutations, a portion of which cause the loss-of-function. The loss-offunction mutations can be mutations accumulated to trigger apoptosis

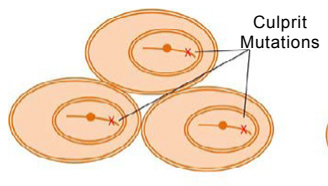

Tumour

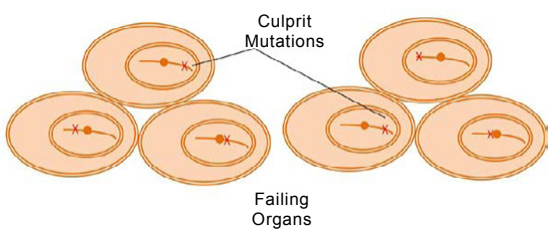

Figure 1: The culprit mutations for carcinogenesis are present in all cells in a tumour as a result of clonal expansion but the culprit mutations for organ failure are present alongside with other mutations. or mutations causing the dysfunction of organ-specific genes. The lossof-function mutations should be commonly observed in the failing organ samples collected from patient groups having a sufficient sample size, although some apoptosis-causing mutations can be non-specific (Figure 1). Together with epigenomic, cistromic, transcriptomic and even interactomic sequencings, the nature of the mutations can be further characterised.

\section{Acknowledgement}

MKC is supported by British Heart Foundation.

\section{References}

1. Hudson TJ, Anderson W, Artez A, Barker AD, Bell C, et al. (2010) International network of cancer genome projects. Nature 464: 993-998.

2. Birney E, Dutta A, Guigo R, Gingeras TR, Weng Z, et al. (2007) Identification and analysis of functional elements in $1 \%$ of the human genome by the ENCODE pilot project. Nature 447, 799-816.

3. Fullwood MJ, Liu MH, Pan YF, Liu J, Xu H, et al. (2009) An oestrogen-receptoralpha-bound human chromatin interactome. Nature 462: 58-64.

4. Lieberman-Aiden E, Van Berkum NL, Williams L, Imakaev M, Ragoczy T, et al. (2009) Comprehensive mapping of long-range interactions reveals folding principles of the human genome. Science 326: 289-293.

5. Busuttil RA, Garcia AM, Cabrera C, Rodriquez A, Suh Y, et al. (2005) Organspecific increase in mutation accumulation and apoptosis rate in CuZnsuperoxide dismutase-deficient mice. Cancer Res 65: 11271-11275.

6. Elchuri S, Oberley TD, Qi W, Eisenstein RS, Jackson Roberts L, et al. (2005) CuZnSOD deficiency leads to persistent and widespread oxidative damage and hepatocarcinogenesis later in life. Oncogene 24: 367-380.

7. Huang TT, Yasunami M, Carlson EJ, Gillespie AM, Reaume AG, et al. (1997) Superoxide-mediated cytotoxicity in superoxide dismutase-deficient fetal fibroblasts. Arch Biochem Biophys 344: 424-432.
*Corresponding author: Mun-Kit Choy, Department of Medicine, University of Cambridge, Addenbrooke's Hospital, Hills Road, UK, E-mail: mkc27@cam.ac.uk

Received January 05, 2012; Accepted January 07, 2012; Published January 10 2012

Citation: Choy MK (2012) Organ genomics: what can we learn? Biol Syst 1:e102. doi:10.4172/2329-6577.1000e102

Copyright: ( 2012 Choy MK. This is an open-access article distributed under the terms of the Creative Commons Attribution License, which permits unrestricted use, distribution, and reproduction in any medium, provided the original author and source are credited. 